\title{
Correction to: Assessing the degree of hydrologic stress due to climate change
}

\section{R. J. Nathan ${ }^{1}$ - T. A. McMahon ${ }^{1}$ - M. C. Peel $^{1}$ - A. Horne ${ }^{1}$}

Published online: 21 October 2019

(C) Springer Nature B.V. 2019

\section{Correction to: Climatic Change}

$$
\text { https://doi.org/10.1007/s10584-019-02497-4 }
$$

In the discussion of Eq. (1), reference is made to an example calculation of the metric that should have been provided in the right-hand panel of Fig. 1. The corrected figure is below:

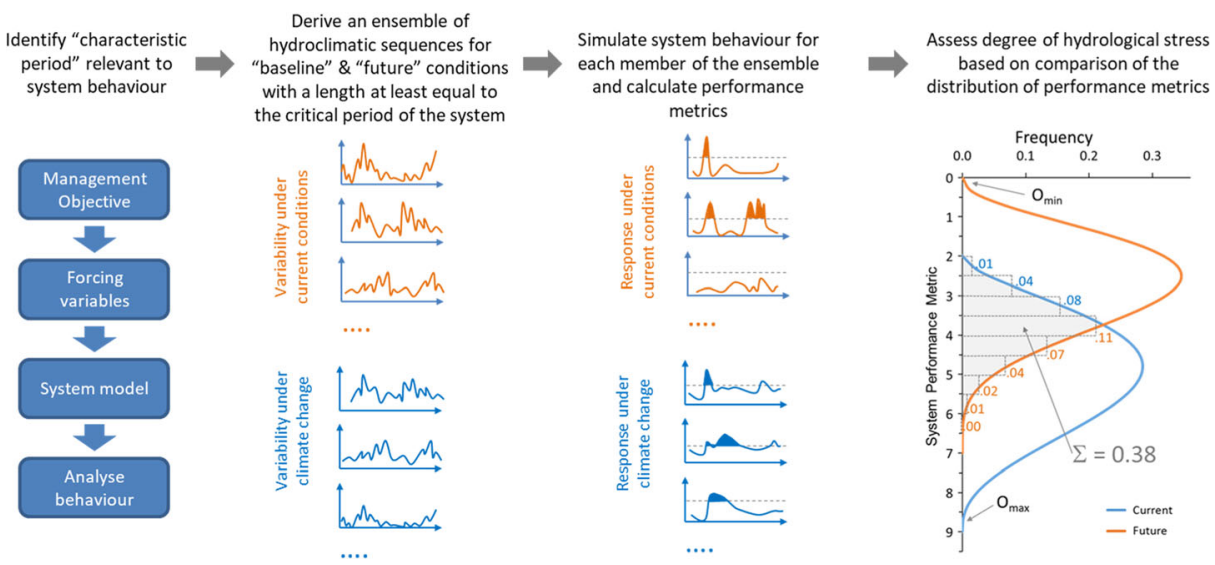

Publisher's note Springer Nature remains neutral with regard to jurisdictional claims in published maps and institutional affiliations.

The online version of the original article can be found at https://doi.org/10.1007/s10584-019-02497-4

R. J. Nathan

rory.nathan@unimelb.edu.au

1 Infrastructure Engineering, University of Melbourne, Grattan St, Parkville, Victoria, Australia 